doi:10.18575/msrs.sm.s.16.13 UDK: 616-006.6 COBISS.RS-ID: 5700632

\title{
Sinhrona resekcija jetrene metastaze i karcinoma rektuma ALPPS tehnikom
}

\section{SAŽETAK}

ALPPS (Associating liver partition and portal vein ligation for staged hepatectomy) operacija se do sada jedino radila u specijalizovanim velikim centrima razvijenih zemalja i to kao samostalna. ALPPS je dvostepena kurativna hepatektomija koja ima indikaciju kada je budući ostatak jetre, tzv. futur liver remnant neadekvatan (FLR).

U radu je prikazan slučaj 63-godišnjaka sa verifikovanim karcinomom rektuma i velikom metastazom u jetri, kod kojeg je ALPPS tehnikom urađena simultana resekcija karcinoma rektuma i jetrene metastaze, sa klinički dobrim rezultatom.

Ključne riječi: ALPPS, metastaza jetre, adenokarcinom rektuma.

(Scr Med 2016:47:74-76)

Zdravko Marić,"

Ozren Kordić,

Velimiv \$krbić,"

Igor Stakić,"

Nina Marić

${ }^{1}$ Klinika za opštu i abdominalnu hirurgiju, Univerzitetsko klinički centar Republike Srpske,

Banja Luka

${ }^{2}$ Klinika za dječije bolesti,

Univerzitetsko klinički centar

Republike Srpske, Banja Luka

\section{Kontakt adresa:}

Zdravko Marić

Ul. Braće Čubrilovića $16 a$

7800 o Banja Luka

Republika Srpska

Bosna i Hercegovina

Mob/ +38765511525

Rad primljen:15.1.2016.

Rad prihvaćen:31.1.2016.

\section{Uvod}

Ekstenzivne/bilobarne jetrene metastaze zahtijevajı ekstenzivne resekcije koje su dozvoljene ako je FLR veći od 27-30\% totalnog volumena. Da bi se postigla sigurna i adekvatna hipertrofija FLR i bezbjedna sekvencijalna hepatektomija, potrebna je ALPPS operacija, odnosno potrebno je uraditi kompletno razdvajanje bolesnog $\mathrm{i}$ zdravog parenhima jetre sa potpunim isključenjem venske, uz prezervaciju arterijske cirkulacije. ALPPS stepen 1 je razdvajanje bolesne jetre (BJ) i FLR, a stepen 2 je odstranjenje BJ nakon 7-21. dana.

\section{Prikaz slučaja}

63-godišnjem muškarcu je kolonoskopijon verifikovana stenotična, infiltrativna masa na rektosigmoidnom spoju koja je patohistoloski adenokarcinom G2. CT je dijagnostifikovao veliku metastazu u jetri, koja je zauzimala $\mathrm{V}$, VI, VI, VIII i djelomično I, IVA i IVB segment (Slika 1.).
Slika 1. CT pacijenta sa metastazom u jetri

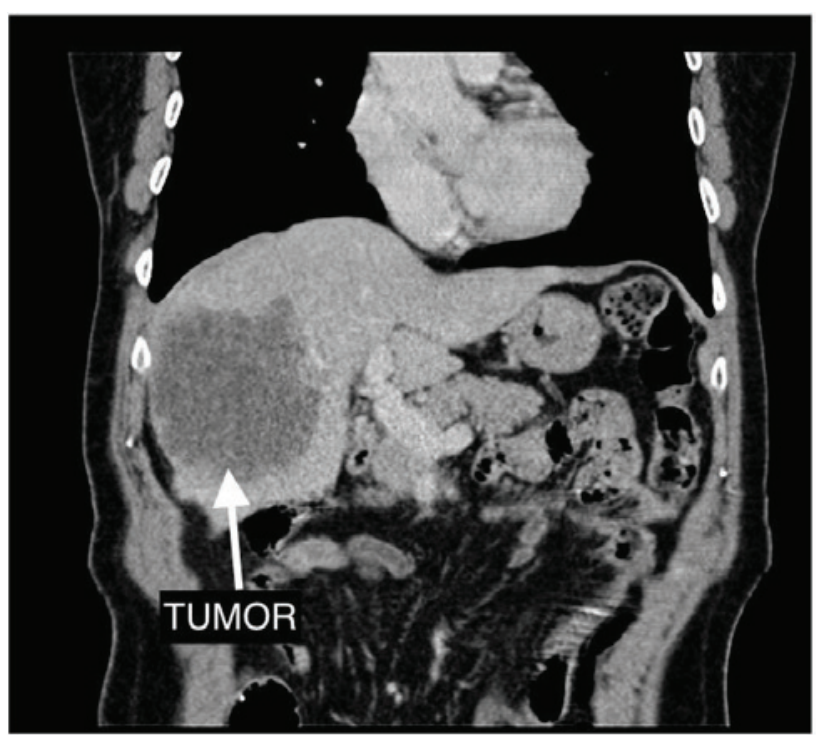


Zbog prijetećeg ileusa, onkološki konzilijum je predložio relativno neodložno operativno liječenje. Urađena je prednja proktosigmoidektomija, totalna mezorektalna ekcizija i staplerska kolorektalna anastonoza.

Mobilizacijon i eksploracijom jetre uz intraoperativni ultrazvuk utvrđeno je da tumorska masa prelazi srednju liniju jetre za oko $1 \mathrm{~cm}$ u zoni segmenta I i $\mathrm{IVb}$, bez infiltracije velikił krvnił sudova i mali FLR. Odlučili smo se za ALPPS postupak tj. kompletno razdvajanje BJ i FLR, uz podvezivanje portalne vene na strani tumora, sa nadom da će se desiti hipertrofija FLR i da će kolorektalna anostonoza biti suficijentna. Poslije holecistektomije i reseciranja svih hepatičnih aksecornih vena, pristupili smo disekciji portalnih struktura. Desna jetrena arterija i desni žıčni kanal su prezervirani, a desna portalna vena je ligirana. Parenhim jetre je razdvojen na granici bolesnog i zdravog tehnikom "Kelly crash". Transferzalne srednje jetrene vene i njihove grane su klipsane i resecirane, a glavne hepatične vene prezervirane (ALPPS stepen 1.) Površina zdravog FLR i ostatka BJ tretirana je hemostiptičkim fibrilaron (Slika 2.).

Slika 2. Operativni nalaz ALPPS stepen 1- razdvojena bolesna i zdrava jetra

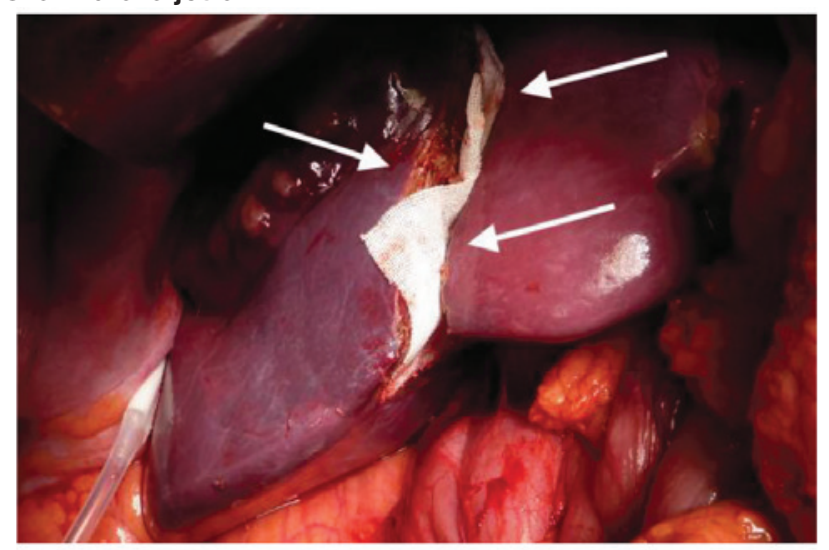

Pacijent je primio dvije doze pune krvi na dan operacije $\mathbf{i}$ još jednu četvrtog postoperativnog dana.

Trećeg postoperativnog dana uradili smo CT volumetriju jetre: TLV (ukupni volumen jetre) je iznosio $2361 \mathrm{~cm} 3$ sa TV (volumenom tumora) 403 cm3. Stvarni ukupni volumen jetre (aTLV) je bio $1958 \mathrm{~cm} 3$. Lijevi dio jetre ili FLR je bio $565 \mathrm{~cm} 3$ ili $28 \%$ od aTLV. Deset dana nakon operacije, CT volumetrija je pokazala ukupni volumen jetre od $1742 \mathrm{~cm} 3$ sa FLV $772 \mathrm{~cm} 3$ ili $44 \%$ od aTLV (Slika 3.).
Slika 3. CT hipertrofisanog FLR desetog postoperativnog dana

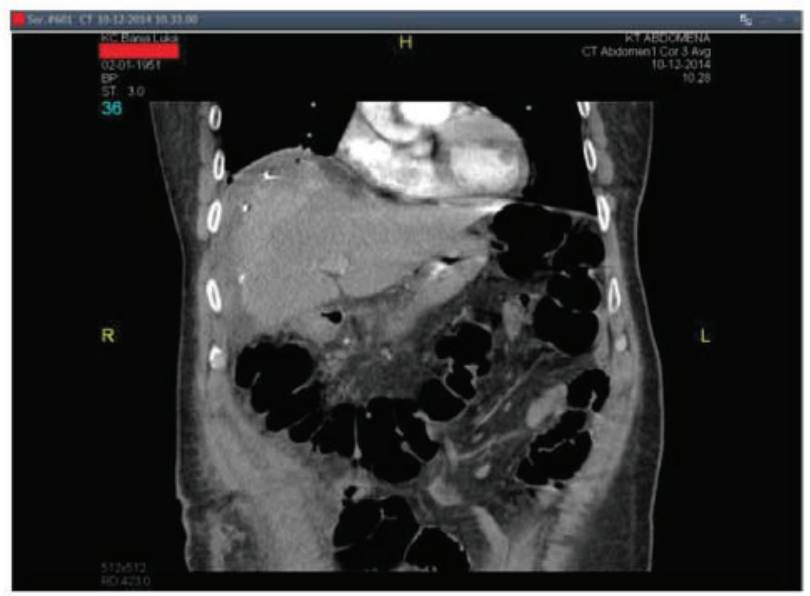

Isti hirurški tim je izvršio desnu hepatektomiju (ALPPS stepen 2) 11. postoperativnog dana. FLR je bio znatno uvećan i normalne boje. Bolesna polovina jetre je imala пеšto bljeđu boju i nije primijećeno da je smanjena. Puls u desnoj arteriji hepatici je bio normalan. Desna arterija hepatica, desni žıčni vod, ranije podvezana desna vena porta i desna hepatična vena su podvezani i resecirani, a desni režanj jetre potpuno oslobođen $i$ izvađen iz trbus̆ne šupljine koja je potom isprana i drenirana sa dva Jackson Pratt drena.

Biohemijski i ultrazvıčni nalazi su kontrolisani prvog, trećeg, sedmog i desetog dana, kada je urađena i CT volumetrija koja je pokazala hipertrofiju FLR (1520 cm3) (Slika 3.). Pacijent je otpušten 21. postoperativnog dana. Imao je adjwantnu citoterapiju. Prilikom kontrole nakon 14 mjeseci, bolesnik je bio bez znakova lokalnog recidiva $\mathrm{i} / \mathrm{ili}$ metastaza.

\section{Diskusija}

Prvi rad u kojem su u aprilu 2011. objavljeni detalji o ALPPS operaciji prenosi iskustvo liječenja 3 pacijenta. 1 U decembru 2015. godine bilo je prijavljeno 148 radova sa preko 600 liječenih pacijenata ALPPS tehnikon. ${ }^{2}$

ALPPS se do sada radila jedino u specijalizovanim velikim centrima razijenih zemalja i to kao samostalna operacija. Do sada se nije preporučivalo sinhrono kombinovanje ALPPS-a sa drugin velikim operacijama. ${ }^{3}$ 
Rani recidivi metastaza u jetri od 20\% do $86 \%$ shučajeva i u plućina u $42 \%$ slučajeva, mnoge su odvratili od ALPPS operacije.4 Bolje razumijevanje metaboličkog suporta i biliohemostaze dali su bolje razultate $\mathrm{i}$ širi interes za ALPPS.

Terens Džekson iz Klivlenda (Ohajo) je 24.11.2014. godine objavio da je uradio prvı sinhronu resekciju karcinoma rektuma i jetrenih metastaza ALPPS tehnikom. ${ }^{5} \mathrm{U}$ vrijeme kada smo mi uradili ovu operaciju, 28.11.2014. godine, nismo bili upoznati s tim radom.

\section{Doprinos autora}

Autori su uradili sinhronu resekciju jetrene metastaze i karcinoma rektuma ALPPS tehnikon samo četiri dana nakon objave o izvođenju prve takve operacije u svijetu. Pored toga, ovo je prvi objavljen shıčaj u svijetı da je isti hirurški tim uradio i resekciju karcinoma rektuma i resekciju jetrene metastaze ALPPS tehnikom.

\section{Reference}

1. Baumgart J., Lang S., Lang $\mathbf{H}$. A new method for induction of liver hypertrophy prior to right trisectionectomy: a report of three cases. HPB (Oxford). $2011 ; 13(2) \div 71-72$.
2. Vivarelli M, Vincenzi P, Montalti R, et al. ALPPS procedure for extended liver resections: a single centre experience and a systematic review. Brung H., ed. PLoS ONE. 2015;10(12):e0144019. doi:10.1371/journal.pone.0144019.

3. Schadde E., Ardiles V., Slankamenac K., Tschuor C., Sergeant G., Amacker N. ALPPS offers a better chance of complete resection in patients with primarily umresectable liver tumors compared with conventional-staged hepatectomies: results of a multicenter analysis. World J Surg. $201438: 1510-1519$.

http://dx.doi.org/10.1007/s00268-014-2513-3 PWid:24748319

4. Oldhafer K. J., Donati M., Jemer R. M., Stang A, Starrou G. ALPPS for patients with colorectal liver metastases: effective liver hypertrophy, but early tumor recurrence. World Journal of Surgery. $2014538(6): 1504-1509$. doi:10.1007/900268-013$2401-2$.

5. Jackson T., Siegel K.A., Siegel C.T. Regcue ALPPS: Intraoperative conversion to ALPPS during synchronous resection of rectal cancer and liver metastasis. Case Reports in Surgery. $2014,2014: 487852$. doi:10.1155/2014/487852.

\title{
Synchronous Resection of Liver Metastasis and Rectal Cancer by ALPPS Technique
}

\begin{abstract}
So far, ALPPS (Associating liver and portal vein partition ligation for staged hepatectomy) operation has been performed only as an individual procedure in big specialized centers in developed countries. ALPPS is two-stage curative hepatectomy for which indication is inadequate, the so-called, future liver remnant (FLR).

In the case report, we described the case of 63-year-old patient with verified colorectal cancer and large metastases in the liver, to whom we conducted simultaneous resection of the rectal cancer and liver metastases using the ALPPS technique with good clinical results.
\end{abstract}

Keywords: ALPPS, liver metastases, adenocarcinoma of the rectum 